\title{
Washing machine using fuzzy logic
}

\author{
Mustafa Demetgul ${ }^{1}$, Osman Ulkir ${ }^{2}$, Tayyab Waqar ${ }^{2}$ \\ ${ }^{1}$ Marmara University, Technology Faculty, Department of Mechatronics Engineering, Istanbul, TURKEY \\ ${ }^{2}$ Marmara University, Institute of Pure and Applied Sciences, Department of Mechatronics, Istanbul, TURKEY
}

Email address:

mdemetgul@marmara.edu.tr (M. Demetgul)

\section{To cite this article:}

Mustafa Demetgul, Osman Ulkir, Tayyab Waqar. Washing Machine Using Fuzzy Logic. Automation, Control and Intelligent Systems. Vol. 2, No. 3, 2014, pp. 27-32. doi: 10.11648/j.acis.20140203.11

\begin{abstract}
For the past few years, different types of control techniques are being used in various fields of industry. Fuzzy logic based control system is one of them. Fuzzy logic uses statements instead of mathematical model for solving a given problem. In this paper, a normal household washing machine, which is used very often, is modeled with the help of Fuzzy logic. Both the simulation and the control of the aforementioned device have been done by using MATLAB's fuzzy logic toolbox.
\end{abstract}

Keywords: Fuzzy Logic, Washing Machine, MatLab, Optimization, Automatic Sensing

\section{Introduction}

Fuzzy logic is a concept which helps computers in making decisions in a way which resembles human behaviors. It helps industry in increasing productivity, creates the opportunity to make production more convenient and most importantly it helps industries in economical terms.

The concept of fuzzy logic was first proposed by Professor Lotfi A. Zadeh in 1965. It was presented in one of his research papers under the name Fuzzy logic or Fuzzy sets $[1,2]$.

The first fuzzy logic based control experiment was conducted by Mamdani [3] in 1974 who designed the fuzzy logic for a steam engine. With his experiment, Mamdani showed how easy it is for a computer to process linguistic statements which was proposed by Zadeh.

After 1980 the use of fuzzy logic based control system becomes common in vacuum cleaners, washing machines, elevators, metro and company operations. Advancements in engineering in recent years have allowed fuzzy logic to be used in many fields [4].

Nowadays fuzzy logic has found its application in several fields like electronic control systems, automotive industries, breaking systems and home electronics etc.

Everyday many home appliances are being upgraded using fuzzy logic to save time and to conserve electricity [5].

Many necessary home appliances like washing machines, dish washers; vacuum cleaners etc. are based on fuzzy logic nowadays. Tiryaki and Kazan's dish washer using fuzzy logic and Alhanjouri and Alhaddad's optimize wash time of washing machine using fuzzy logic are one of few studies which are based on fuzzy logic [5,6].

Alhanjouri and Alhaddad's washing machine takes dirt type and degree of dirtiness as inputs while wash time is the only output of the system [6].

Agarwal controlling the washing time using fuzzy logic control. Type of dirt, dirtness of clothes were selected as input [7].

Also aim to reduce wasting of electric and water. The washing machine fuzzy controller neural network is researched deeply, which is based on fuzzy logic, neural network and its learning algorithm [8-9].

Kumar and Haider aim to reduce washing time. Quantity and dirtiness were selected as input [10].

The device which is being presented in this study has 4 different inputs depending on which 5 different outputs are being controlled by using fuzzy logic.

In contrast to the previous studies, the washing machine discussed in this paper has more inputs and outputs for example depending on the sensitivity and the quantity of cloths, washing machine will automatically adjust its washing speed, amount of detergent, hotness of water and water level. It will help us in conserving water and detergent while washing our cloths.

In this paper, fuzzy logic control for a very common household, i.e. washing machine, has been developed. The modeling of washing machine has been based on the parameters regarding washing of cloths. 


\section{Fuzzy Logic}

In crisp logic, classifications are definite, i.e. a member is either a part of group or not. It can't be both. In short, crisp logic has two values 0 and 1 . In contrast, fuzzy logic can work in complex conditions similar to humans.

If we consider solving a problem regarding human age by using both the crisp and fuzzy logic we can understand the difference between them. Figure 1 shows crisp logic while fuzzy logic can be seen in figure 2 .

According to figure 1, people in between 0-30 years will be considered young; 30-50 years old will be considered middle aged and above 50 will be considered old.

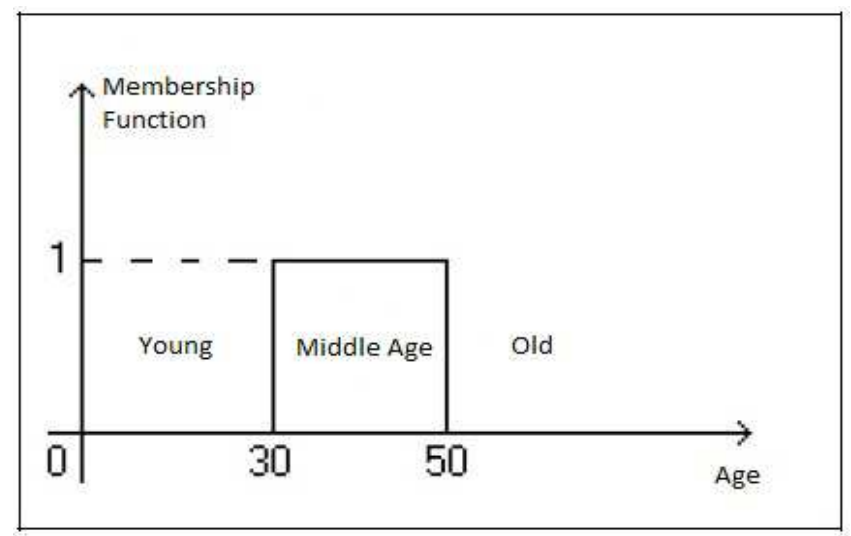

Figure 1. Crisp Logic [11]

According to those laws, a 31 years old person will be considered middle age while a 29 years old will be considered young.

If we examine this condition using fuzzy logic then a 30 years old person, in an appropriate proportion, will be considered both young and middle age (figure 2). Unlike Crisp logic, Fuzzy logic doesn't have only 0 and 1 . It is more flexible thus a more realistic approach can be applied [12].

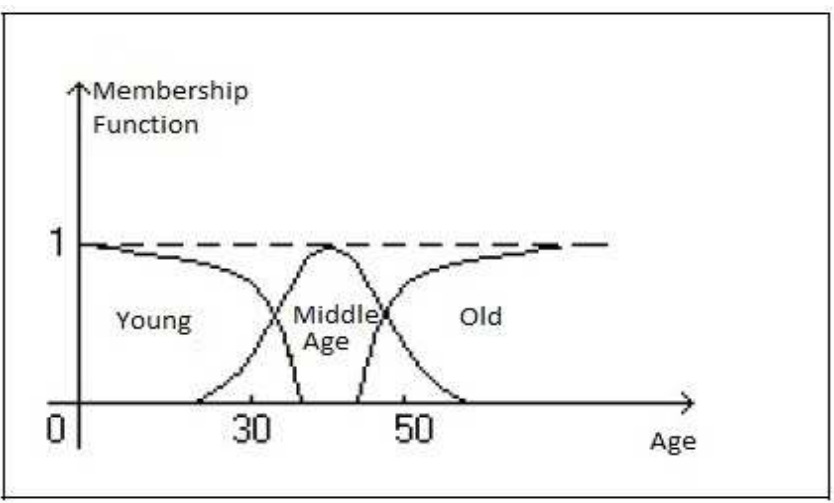

Figure 2. Fuzzy Logic [11]

\subsection{Fuzzy Logic System Structure}

The basic elements of fuzzy logic; Fuzzy inputs, outputs, rules and defuzzification; are shown in figure 3. [13-14]

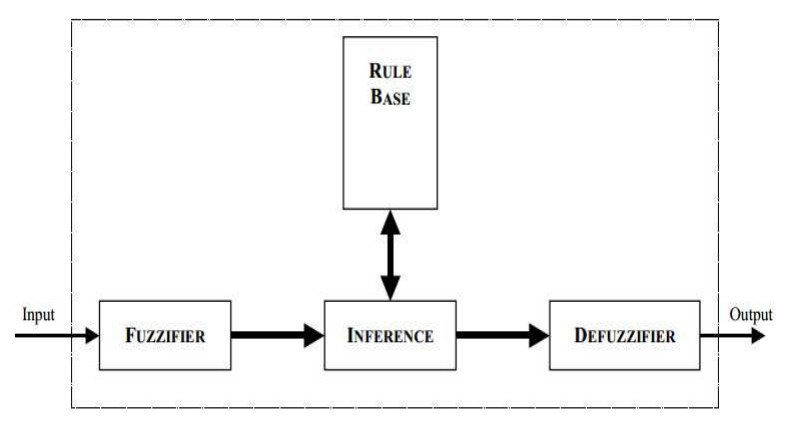

Figure 3. Structure of a fuzzy logic system [12, 13]

Fuzzy take the information from a system; which is in normal language; and converts it to values. The values of input quantities, which are associated with of membership functions, are given in form of words such as small, smallest [2].

Input and output variables of fuzzy system are determined and their values i.e. less, much, hot and cold etc. are being selected. Afterwards, rules are being developed and by using those rules input and output relationship is developed.

Outputs are being produced by using fuzzified inputs and rules which are being determined. Those fuzzified outputs must be converted to real values so that they can be used in real systems. This whole process is known is defuzzification. [13].

\section{Fuzzy Logic Modeling of Washing Machine}

To model a system using fuzzy logic, the first step is to determine the inputs and outputs of it. A washing machine's most important duty is to clean the cloths without damaging them. In order to achieve it, the output parameters of fuzzy logic, which are related to washing, must be paid importance. Inputs and outputs of fuzzy logic system are shown in figure 4.

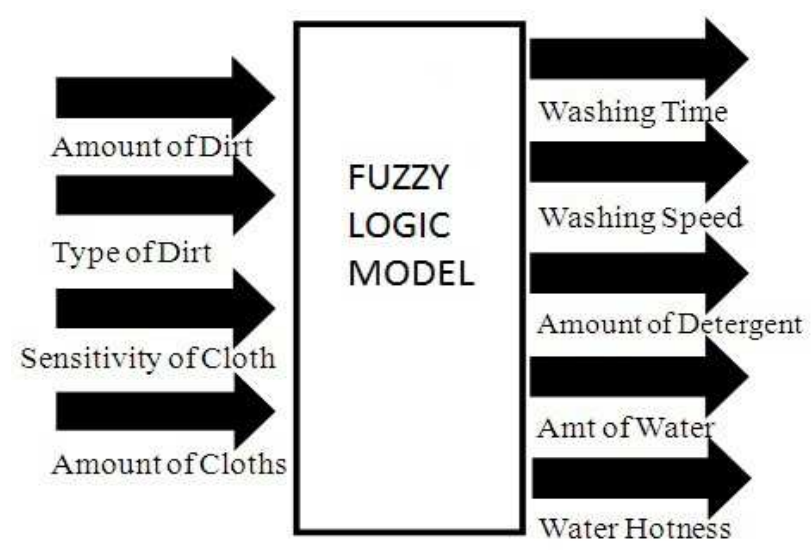

Figure 4. Inputs and Outputs of the System

Using fuzzy logic, input parameters such as Amount of dirt, type of dirt, sensitivity of cloth and amount of cloths, will help washing machine to achieve economical wash. 
The input and output parameter's membership function values, names, upper and lower limits are being set based on a given problem. The membership functions, with upper and lower limits, of input and output parameter's are shown in figure 5 and 6 respectively. Figure 5 and figure 6 show membership functions of input and output respectively and also their upper and lower limits.

After determining the membership functions and their upper and lower limits required for the modeling of necessary parameters, a total of 81 rules have been established to define relationship among those parameters.

In order to apply fuzzy logic to washing, it is necessary to establish fuzzy logic rules. These rules can be seen in Table 1.

Input Parameters:

1. Amount of Dirt

2. Type of Dirt

3. Sensitivity of Cloth

4. Amount of Cloths

Output Parameters:

1. Washing Time

2. Washing Speed

3. Amount of Detergent

4. Amount of Water

5. Water Hotness

Table 1. Fuzzy Logic Rule Table

\begin{tabular}{|c|c|c|c|c|c|c|c|c|c|}
\hline & \multicolumn{4}{|c|}{ INPUTS } & \multicolumn{5}{|c|}{ OUTPUTS } \\
\hline & 1 & 2 & 3 & 4 & 1 & 2 & 3 & 4 & 5 \\
\hline 1 & $\mathrm{~S}$ & NG & LS & $\mathrm{S}$ & S & LW & LT & LT & LW \\
\hline 2 & $\mathrm{~S}$ & G & LS & $\mathrm{L}$ & LG & M & $\mathrm{MN}$ & $\mathrm{MN}$ & $\mathrm{H}$ \\
\hline 3 & $\mathrm{~S}$ & NG & NS & M & M & M & LT & LT & LW \\
\hline 4 & M & M & NS & M & M & M & $\mathrm{N}$ & $\mathrm{N}$ & $\mathrm{N}$ \\
\hline 5 & M & M & LS & $\mathrm{S}$ & S & M & $\mathrm{N}$ & $\mathrm{N}$ & $\mathrm{N}$ \\
\hline 6 & M & M & LS & $\mathrm{L}$ & LG & $\mathrm{H}$ & $\mathrm{MN}$ & $\mathrm{MN}$ & $\mathrm{N}$ \\
\hline 7 & M & M & VS & M & S & M & $\mathrm{N}$ & $\mathrm{N}$ & $\mathrm{N}$ \\
\hline 8 & $\mathrm{~L}$ & G & VS & $\mathrm{L}$ & VL & $\mathrm{VH}$ & $\mathrm{MN}$ & $\mathrm{MN}$ & $\mathrm{H}$ \\
\hline 9 & $\mathrm{~L}$ & G & LS & M & LG & $\mathrm{H}$ & $\mathrm{MN}$ & $\mathrm{MN}$ & $\mathrm{H}$ \\
\hline 10 & $\mathrm{~L}$ & NG & NS & $\mathrm{L}$ & VL & $\mathrm{H}$ & $\mathrm{N}$ & $\mathrm{N}$ & LW \\
\hline
\end{tabular}

$\mathrm{S}=$ Small, $\mathrm{M}=$ Medium, $\mathrm{L}=$ Large, $\mathrm{NG}=$ Not Greasy, $\mathrm{G}=$ Greasy, $\mathrm{LS}=$ Less Sensitive, NS $=$ Normal Sensitive, VS $=$ Very Sensitive, $\mathrm{S}=$ Short, LG $=$ Long, $\mathrm{VL}=$ Very Long, $\mathrm{LW}=$ Low, $\mathrm{H}=$ High, $\mathrm{VH}=$ Very High, $\mathrm{LT}$ $=$ Little, $\mathrm{N}=$ Normal, $\mathrm{MN}=$ Many.
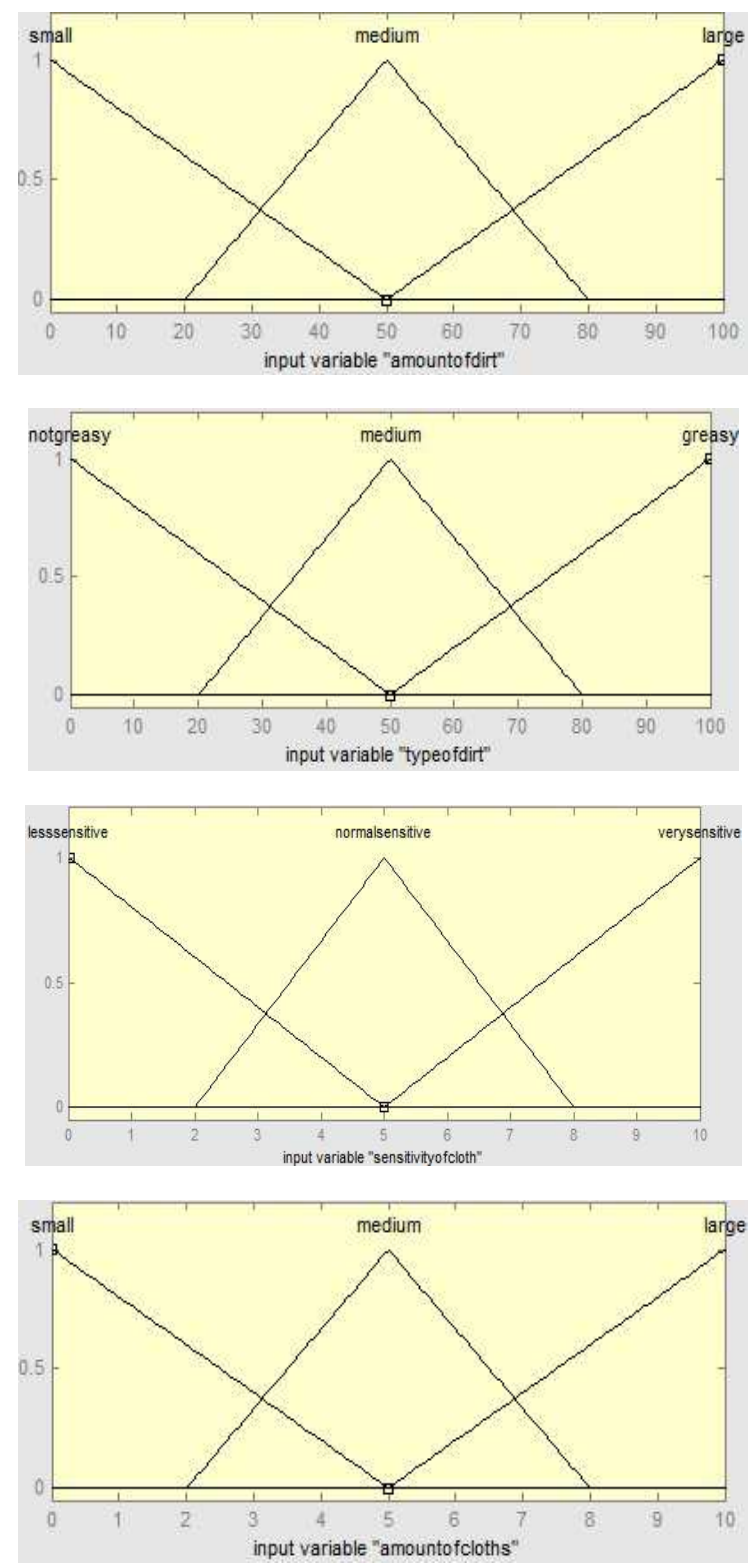

Figure 5. Fuzzy logic input membership functions

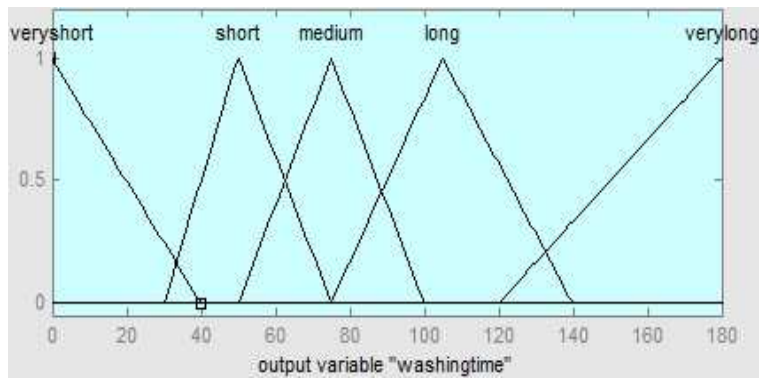



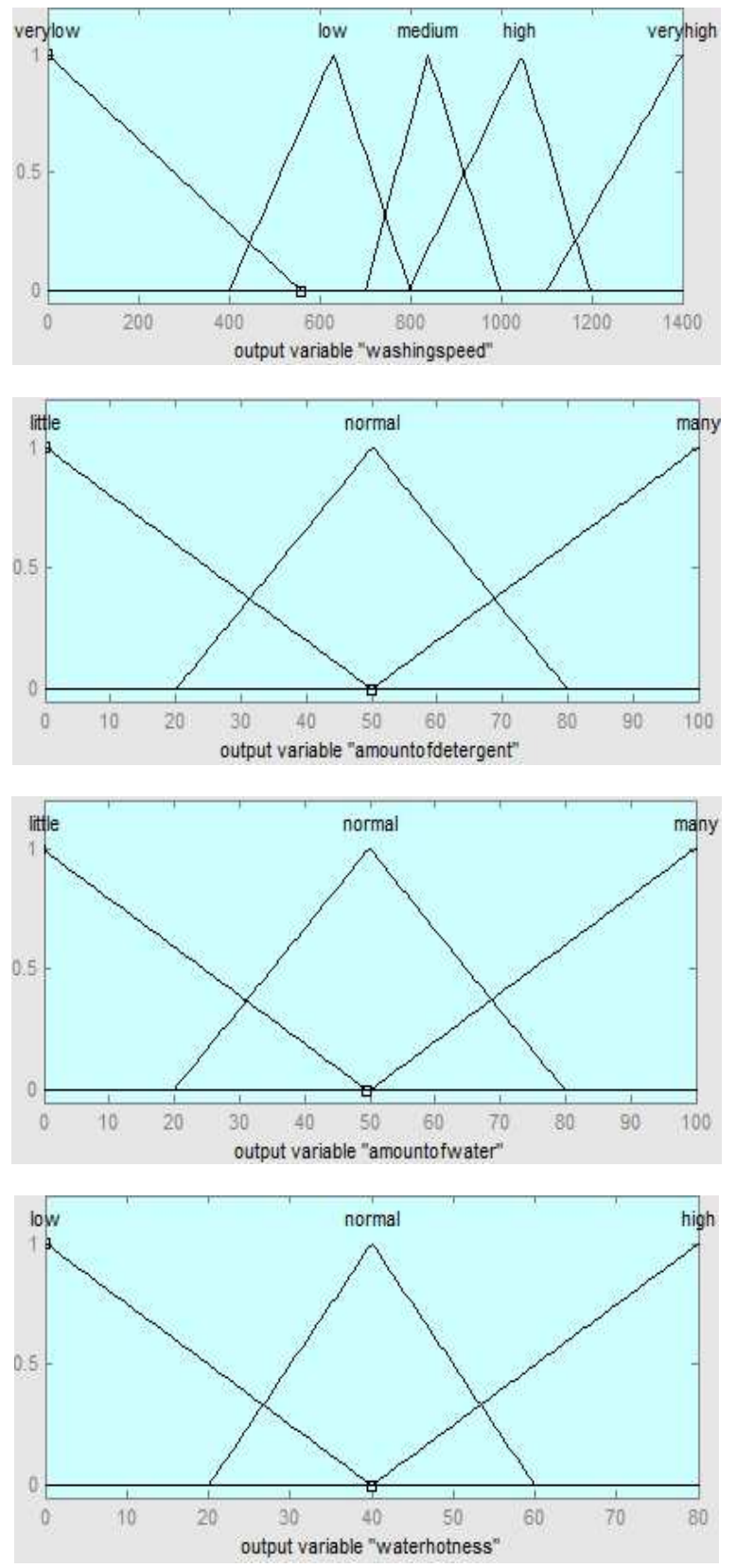

Figure 6. Fuzzy logic output membership functions

Fuzzy rules have been established for the modeling of washing machine. The whole system has been developed by using MATLAB's fuzzy logic toolbox.

The results of those rules, which have been determined by applying Min-Max operator, are illustrated in the form of 3D graphs in figure $7,8,9,10,11,12$. These figures show the relationship between input and output parameters.

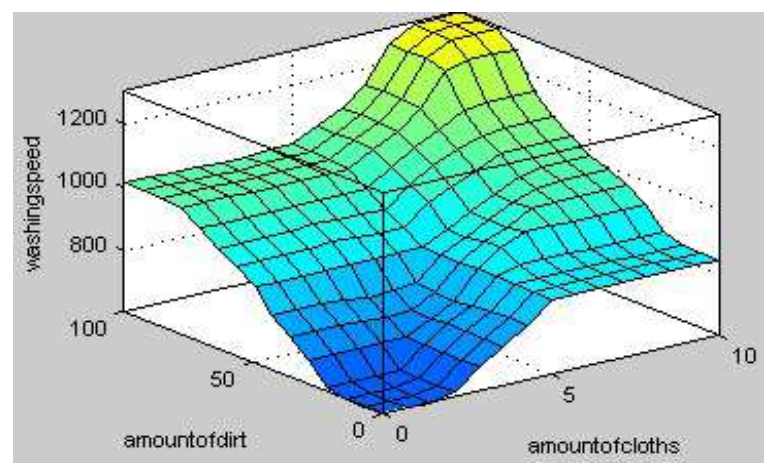

Figure 7. Amount of cloths and amount of dirt affects the washing speed

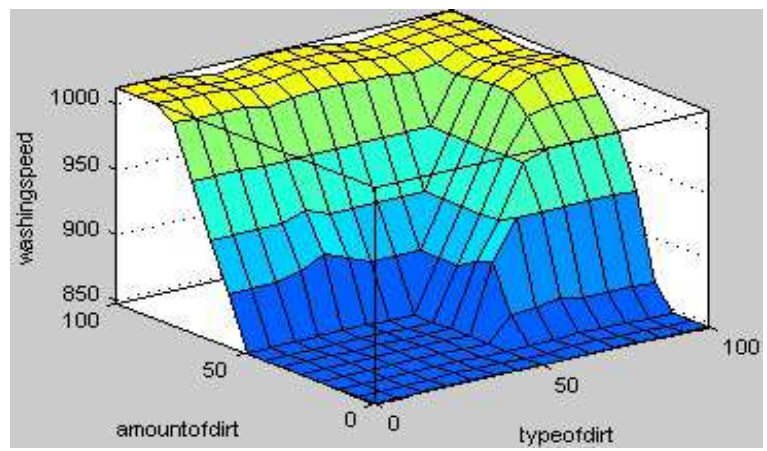

Figure 8. Type of dirt and amount of dirt affects the washing speed

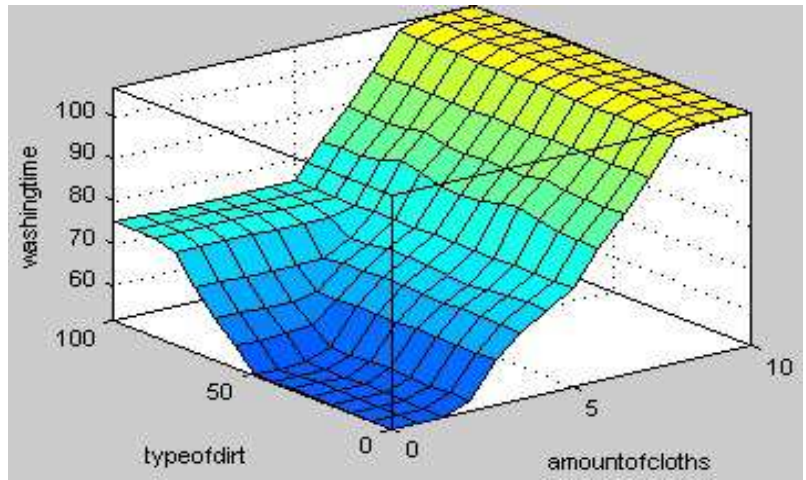

Figure 9. Amount of cloths and type of dirt affects the washing time

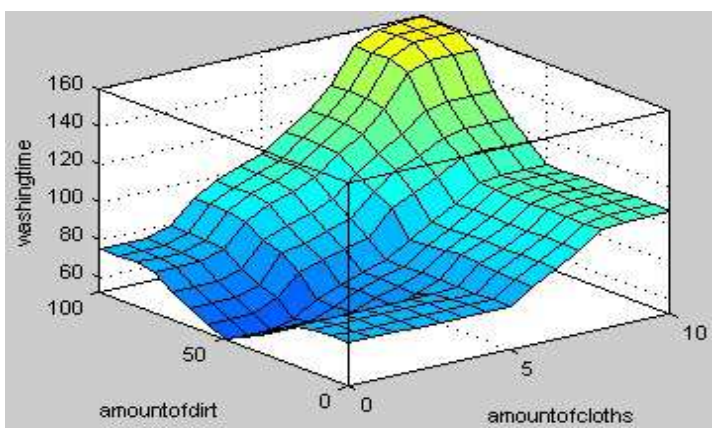

Figure 10. Amount of dirt and amount of cloths affects the washing time 


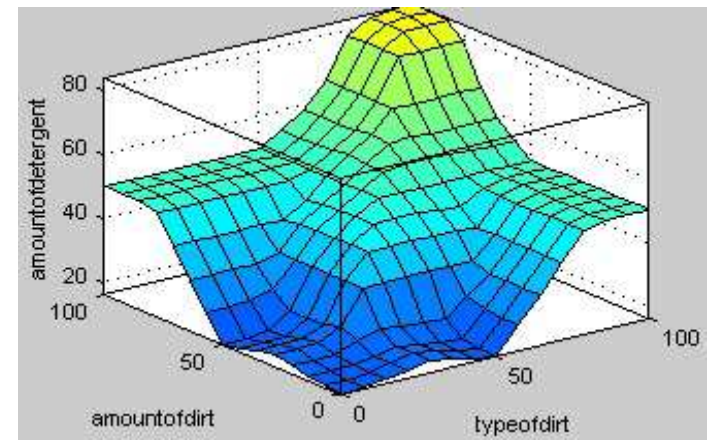

Figure 11. Type of dirt and amount of dirt affects the amount of detergent

As can be seen in figure 7, washing speed isn't affected much by the amount of cloths. Amount of dirt and sensitivity of cloth are the most important factors which regulate the washing speed.
Figure 9 shows that washing time is directly proportional to the amount of cloths.

Figure 12 tells us that water hotness is very much affected by the type of dirt present in the cloths.

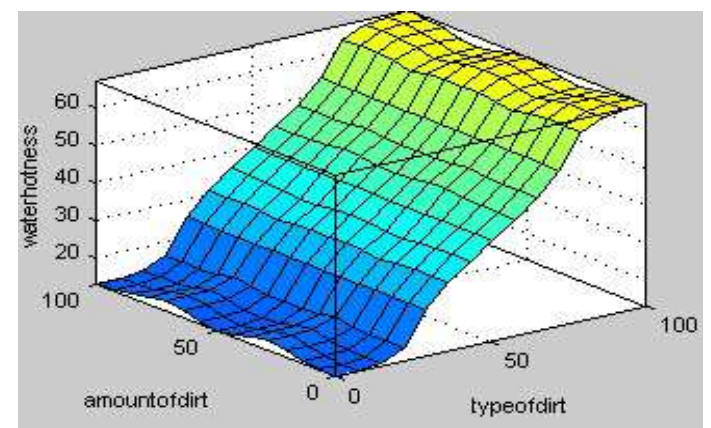

Figure 12. Type of dirt and amount of dirt affects the water hotness

Table 2. Fuzzy logic outputs in response to the inputs

\begin{tabular}{|c|c|c|c|c|c|c|c|c|}
\hline \multicolumn{4}{|c|}{ INPUTS } & \multicolumn{5}{|c|}{ OUTPUTS } \\
\hline $\begin{array}{c}\text { Amount of } \\
\text { Dirt }\end{array}$ & Type of Dirt & $\begin{array}{c}\begin{array}{c}\text { Sensitivity of } \\
\text { cloth }\end{array} \\
\end{array}$ & $\begin{array}{c}\text { Amount of } \\
\text { Cloths }\end{array}$ & $\begin{array}{c}\text { Washing } \\
\text { Time }\end{array}$ & $\begin{array}{c}\text { Washing } \\
\text { Speed } \\
\end{array}$ & $\begin{array}{c}\text { Amount of } \\
\text { detergent }\end{array}$ & $\begin{array}{c}\text { Amount of } \\
\text { Water }\end{array}$ & $\begin{array}{c}\text { Water } \\
\text { Hotness }\end{array}$ \\
\hline$\% 50$ & $\% 50$ & 5 & 5 & $95 \mathrm{~d}$ & $1000 \mathrm{~d} / \mathrm{d}$ & $\% 45,8$ & $\% 48,5$ & $60{ }^{\circ} \mathrm{C}$ \\
\hline$\% 88.7$ & $\% 82.2$ & 1.8 & 7.67 & $140 \mathrm{~d}$ & $1200 \mathrm{~d} / \mathrm{d}$ & $\% 60,5$ & $\% 60$ & $70^{\circ} \mathrm{C}$ \\
\hline$\% 62$ & $\% 66.4$ & 3.67 & 6.2 & $128 \mathrm{~d}$ & $1100 \mathrm{~d} / \mathrm{d}$ & $\% 52$ & $\% 55,8$ & $65^{\circ} \mathrm{C}$ \\
\hline$\% 24.7$ & $\% 20.4$ & 7.27 & 3.27 & $60 \mathrm{~d}$ & $700 \mathrm{~d} / \mathrm{d}$ & $\% 30,5$ & $\% 35$ & $40^{\circ} \mathrm{C}$ \\
\hline$\% 11.3$ & $\% 11.2$ & 8.73 & 1.93 & $40 \mathrm{~d}$ & $400 \mathrm{~d} / \mathrm{d}$ & $\% 20,5$ & $\% 30$ & $30^{\circ} \mathrm{C}$ \\
\hline
\end{tabular}

Table 2 describes the variation in the output parameters, in response to the given inputs, of the washing machine.

\section{Conclusion}

In this paper, rule based fuzzy logic for washing machine has been developed. It will help in achieving economical washing procedure by sensing amount of dirt, type of dirt, sensitivity of cloth and amount of cloths. Based on input parameters, i.e. amount of dirt, type of dirt, sensitivity of cloth and amount of cloths; washing speed, washing time, water hotness and amount of detergent will be regulated on the output. Due to this adjustment of output parameters, cloths will come out cleaner and it will also make the whole washing process economical by reducing the amount of water, detergent, electricity and time.

Results of this simulation based study are pretty good which is clearly shown in the graphs. When we compare the results we have gotten with the expected results, it shows that this model, which has been developed in this paper, is extremely useable.

MATLAB/Fuzzy logic toolbox has been used to materialize this study. It can be practically implemented by using necessary mechanical and electronics engineering concepts.

\section{References}

[1] Zadeh, L.A., "Fuzzy Sets", Information and Control,8,338353, 1965.

[2] Elmas, C., "Bulanik Mantik Denetleyicileri", ISBN 975347-613-2, 2003

[3] Mamdani, E.H., “Application of Fuzzy Algorithms for Control of Simple Dynamic Plant”, Proc. IEEE, 121(12), 1585-1588, 1974.

[4] Şen Z., "Bulanık (Fuzzy) Mantık Ve Modelleme İlkeleri”, Bilge Sanat Yapım Yayınevi, İstanbul, 2001.

[5] Tiryaki, A.E., Kazan, R., "Bulasik Makinesinin Bulanik Mantik ile Nodellenmesi", Muhendis ve Makina Dergisi, Cilt:48, Sayi:565, Sakarya.

[6] Alhanjouri, M. and A. Alhaddad, A., "Optimize Wash Time of Washing Machine Using Fuzzy Logic", Islamic University of Gaza.

[7] Agarwal, M. (2007). Fuzzy logic control of washing machines.URL:http://softcomputing.tripod.com/sample_ter mpater:pdf.

[8] Zhen. A. and Feng R. G., "The design of neural network fuzzy controller in washing machine," in Proc. 2012 International Conference on Computing, Measurement, Control and Sensor Network (CMCSN), Shanxi, China, 136-139, 2012. 
[9] Virkhare N., Jasutkar R.W., Neuro-Fuzzy Controller Based Washing Machine, International Journal of Engineering Science Invention, 3(1), 48-51, 2014.

[10] Kumar D., Haider Y., Fuzzy Logic Based Control System for Washing Machines, International Journal of Computer Science and Technology, 4(2), 198-200, 2013.

[11] Ozek, A., Sinecen, M., "Klima Sistem Kontrolunun Bulanik Mantik ile Modellenmesi", Pamukkale Universitesi Muhendislik Fak. Muhendislik Bilimleri Dergisi, 10(3), 353-358, 2004.
[12] Tuncer, S. 1999. “Değișken Hizlı Sürücü Sistemleri İçin Fuzzy Denetleyicili Yeni Bir Algoritmanın Geliştirilmesi ve Uygulaması", F. Ü., Fen Bilimleri Enstitüsü, Yüksek Lisans Tezi.

[13] Dadone, P., "Design Optimization of Fuzzy Logic Systems", Doctor of Philosophy in Electrical Engineering, Virginia Polytechnic Institute and State University, 2001.

[14] Mendel, J.M., "Fuzzy Logic Systems for Engineering: A Tutorial", Proceedings of the IEEE, 83(3), 1995. 